\title{
Article \\ A Metallochaperone HIPP33 Is Required for Rice Zinc and Iron Homeostasis and Productivity
}

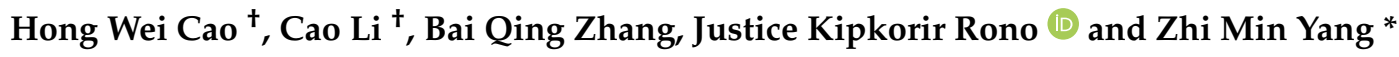 \\ Department of Biochemistry and Molecular Biology, College of Life Sciences, Nanjing Agricultural University, \\ Nanjing 210095, China; 2018116108@njau.edu.cn (H.W.C.); 2020816147@njau.edu.cn (C.L.); \\ 2016116120@njau.edu.cn (B.Q.Z.); justicekrono@yahoo.com (J.K.R.) \\ * Correspondence: zmyang@njau.edu.cn; Tel.: +86-25-839-5057 \\ t These authors contributed equally to the study.
}

Citation: Cao, H.W.; Li, C.; Zhang, B.Q.; Rono, J.K.; Yang, Z.M. A Metallochaperone HIPP33 Is Required for Rice Zinc and Iron Homeostasis and Productivity. Agronomy 2022, 12, 488. https:// doi.org/10.3390/agronomy12020488 Academic Editors: Kirsten Brandt and Alessio Aprile

Received: 25 December 2021

Accepted: 14 February 2022

Published: 16 February 2022

Publisher's Note: MDPI stays neutral with regard to jurisdictional claims in published maps and institutional affiliations.

Copyright: (C) 2022 by the authors. Licensee MDPI, Basel, Switzerland. This article is an open access article distributed under the terms and conditions of the Creative Commons Attribution (CC BY) license (https:// creativecommons.org/licenses/by/ $4.0 /)$

\begin{abstract}
Both zinc (Zn) and iron (Fe) are essential micro-nutrients for plant growth and development, yet their levels in plants are tightly regulated to prevent either deficiency or phytotoxicity. In agronomic reality, such an imbalance of metal bioavailability to crops occurs frequently. Thus, mining genetic resources to improve crop traits relevant to metal homeostasis is a great challenge to ensure crop yield and food quality. This study functionally identified an uncharacterized metallochaperone family HIPP protein gene Heavy Metal Associated Isoprenylated Plant Proteins 33 (OsHIPP33) in rice (Oryza sativa). OsHIPP33 resides in the nucleus and plasma membrane and constitutively expresses throughout the lifespan. Transcription of OsHIPP33 is not induced by deprivation of $\mathrm{Zn}$ and Fe but upregulated under excessive $\mathrm{Zn}$ and Fe stress. In a short-term (one month) hydroponic study with the normal $\mathrm{Zn}$ and Fe supply, there were no significant changes in the growth and metal accumulation between the knockout (OsHIPP33) or knockdown (RNA interference) mutant lines and wild-type, while the long-term field trials (for two successive years) demonstrated that the mutation of OsHIPP33 significantly compromised the rice growth and development (such as rice leave tissues, panicle length, spikelet fertility, seed weight per plant, 1000-grain weight, etc.), with the mature grain yield of OsHIPP33 and RNAi lines reduced by $52 \%$ and $12-15 \%$ respectively, compared with wild-type. Furthermore, the accumulation of $\mathrm{Zn}$ and Fe in rice straw, husk and brown rice was also reduced. These results suggest that the disruption of OsHIPP33 can dampen rice agronomic traits, signifying that OsHIPP33 expression is required for $\mathrm{Zn}$ and Fe homeostasis and subsequent production of rice grains.
\end{abstract}

Keywords: metallochaperone; HIPP33; rice; zinc; iron; grain

\section{Introduction}

Zinc is an essential micro-nutritional element for diverse biological functions in plants. One central role is as key cofactor for many metalloenzymes and other proteins actively participating in biological processes including conformation of structured proteins, activation of transcription factors or mediation of protein-protein interactions [1]. Despite its importance, $\mathrm{Zn}$ intake from staple food crops like cereals is inadequate in more than two billion people, accounting for $17.3-30 \%$ of the world population [2]. Most types of soil are unable to provide enough free $\mathrm{Zn}$ accessible to plants ( $\mathrm{Zn}$ efficiency) for healthy plant growth and development [3]. As a consequence, zinc starvation symptoms appear with stunted plant growth, manifested by shorter internodes, smaller size of leaves, necrosis of root tips and young leaf yellowing [4]. Iron is another Zn-equivalent essential metal and also serves as a cofactor of diverse enzymes, playing an indispensable role in photosynthesis, respiration and many other metabolic processes [5]. Although most soils on Earth have sufficient iron elements, their real availability to plants is limited. Iron deficiency also causes the arrest of plant growth, leaf chlorosis, reduced reproductively, and low quality of seed [6]. 
Regulation of $\mathrm{Zn}$ and Fe homeostasis in plants largely depends on a group of meal transporters relevant to $\mathrm{Zn}$-regulated transporter, Iron-regulated transporter-like Protein (ZIP), Metal Tolerance Protein (MTP), Natural Resistance-Associated Macrophage Protein (NRAMP), Heavy Metal ATPase (HMA) family members and others [7-9]. With regard to Fe transporters, two canonical uptake routines have been so far identified in dicots and graminaceous plants. The first routine in dicots such as Arabidopsis concern (1) the initial rhizosphere acidification by $\mathrm{H}^{+}$-adenosinetriphosphatases, followed by proton release to facilitate Fe solubility, and (2) the reduction of $\mathrm{Fe}^{3+}$ to $\mathrm{Fe}^{2+}$ catalyzed by a reductase, which is then absorbed into root cells by the iron transporter Iron-Regulated Transporter (IRT1) [10]. Graminaceous species such as rice and wheat utilize the second way of releasing phytosiderophores into the rhizosphere to chelate $\mathrm{Fe}^{3+}$ and develop a $\mathrm{Fe}^{3+}$-phytosiderophores complex which is further transported into roots by some transporters such as YELLOW STRIPE 15-like (YSL15) [11]. OsZIP6, for example, functionally regulates a transition metal iron transport in rice [12]. To date, a number of metal transporters have been identified involving $\mathrm{Zn}$ and Fe absorption, transport and allocation [13].

In addition to the metal transporters, there are other types of metal-binding proteins involved in the regulation of metal accumulation, allocation and homeostasis. Recently, a unique protein family has emerged as a metallochaperone to coordinate metal transport [14-16]. Heavy metal-associated isoprenylated plant proteins (HIPPs) are one of the metallochaperone subfamily proteins and use diverse mechanisms to mediate metal homeostasis and promote growth, development and adaptation to abiotic or environmental stresses [17-19]. HIPPs share a conserved metal-bonding core that interacts with metal ions and distinct isoprenylated motifs consisting of glycine- or proline-rich repeat domains [14]. Thus far, a large subset of HIPP genes has been identified from higher plant species; 45 in Arabidopsis thaliana, 59 in Oryza sativa, 74 in Populus tomentosa, 52 in Setaria angustifolia and five in Selaginella officinalis. These genes were divided into five different clusters based on their sequence identity $[14,16]$. Yeast (Saccharomyces cerevisiae) anti-oxidant1 (Atx1) is a copper $(\mathrm{Cu})$ chaperone that delivers $\mathrm{Cu}$ to the copper-requiring oxidase Fet3p for metal uptake and metabolism [20]. Its homolog ATXl in higher plants is also a Cu-binding protein that transfers $\mathrm{Cu}$ to some targets for physiological processes [21]. In rice, knocking out OsATX1 enhances $\mathrm{Cu}$ accumulation in roots and may function with several P1B-ATPases for $\mathrm{Cu}$ homeostasis [22]. Despite the fact that many metallochaperone genes are identified in plants, only a few of them have been functionally characterized for metal uptake and accumulation during plant growth and development.

Rice is one of the most important food crops and requires multi-mineral nutrients to support its growth and reproduction. In this study, we identified a new HIPP family gene, OsHIPP33, which was isolated from our previous metal-stress responsive transcriptome [16]. Since its function has not been reported before, our studies show that expression of OsHIPP33 is required for $\mathrm{Zn}$ and Fe accumulation, proper growth and seed development. The purpose of this paper is to examine the role of OsHIPP33 in maintaining the steady-state of $\mathrm{Zn}$ and $\mathrm{Fe}$ in rice plants by hydroponic culture and field trial approaches.

\section{Materials and Methods}

\subsection{Plant Materials and Metal Treatments}

Rice (wild-type Nipponbare) seeds were sterilized with alcohol (75\%) for $2 \mathrm{~min}$ and sodium hypochlorite $(1.0 \%)$ solution for $10 \mathrm{~min}$. After thoroughly bathing with distilled water, seeds were germinated at $28^{\circ} \mathrm{C}$ for $72 \mathrm{~h}$. For the hydroponic study, the germinating seedlings were transferred to a net floating on the half-strength Kimura B nutrient solution. Two-week-old plants continued to grow in the nutrient solution with (normal or excess levels) or without $\mathrm{Zn}, \mathrm{Fe}, \mathrm{Cu}$ or Mn. Cadmium (Cd) serves as a non-essential equivalent metal for the test. Plants were grown in a growth chamber under the condition of a $16 \mathrm{~h}$ luminous $\left(250 \mu \mathrm{molm}^{-2} \mathrm{~s}^{-1}\right.$ light intensity, $\left.28^{\circ} \mathrm{C}\right)$ and $8 \mathrm{~h}$ dark $\left(26^{\circ} \mathrm{C}\right)$ photoperiod with relative $60 \pm 10 \%$ humidity [23]. 
For paddy field trials, three week-old rice seedlings prepared in the growth chamber (the condition is the same as hydroponic culture) were transferred and planted in the open paddy soil. The soil used in this study is the local realistic farmland, characterized as Nanjing yellow brown soil $\left(117.02^{\circ}\right.$ east longitude, $28.23^{\circ}$ north latitude) [24], with the following physical and chemical features: (1) textures (\%): sand (67.2), clay (13.3) and silt (19.5); (2) total organic carbon: $2.13 \%$, soil organic matter: $3.67 \%$, cation exchange capacity: $21.40 \mathrm{cmol} \cdot \mathrm{kg}^{-1}$ and total nitrogen: $0.21 \%$; and (3) major mineral elements: Ca: $2.04 \mathrm{~g} \cdot \mathrm{kg}^{-1}$, Fe: $13.80 \mathrm{~g} \cdot \mathrm{kg}^{-1}, \mathrm{Zn}: 43.78 \mathrm{mg} \cdot \mathrm{kg}^{-1}$, Mn: $241.94 \mathrm{~g} \cdot \mathrm{kg}^{-1}$, and $\mathrm{Cu}: 12.11 \mathrm{mg} \cdot \mathrm{kg}^{-1}$. Biological triplicates with completely randomized blocks (each block contains 300 plants) were designed. Field trials for the rice varieties were conducted in Nanjing for two successive years (28 May-20 September 2020 and 20 May-1 September 2021). The rice varieties were grown under natural conditions. When harvested, the mature plants were separately sampled according to their special tissues or organs such as leaves, panicles or grains (husk and brown rice) and determined for agronomic traits and metal concentrations.

\subsection{Analysis of Gene Structural Sequences}

Putative OsHIPP33 (LOC_Os02g30650) and related HIPP genes were obtained from the Rice genome (http:/ / rice.plantbiology.msu.edu) and NCBI BLAST database (http: //ncbi.nlm.nih.gov/blast). The HMA domain was predicted by the Simple Modular Architecture Research Tool (SMART, http: / / smart.embl-heidelberg.de). The amino acid sequences of OsHIPP33 and its homologs in rice were loaded onto MEGA 6.0 to construct a phylogenetic neighbor-joining tree with 1000 replications. The protein sequence of OsHIPP33 and its close homolog was aligned using DNAMAN.

\subsection{Transcript Analysis by Quantitative RT-PCR}

Rice tissues were sampled and total RNAs were isolated using Trizol reagent, with DNase I treatment to remove DNA in the sample. The desirable RNA samples were used as templates to synthesize cDNA using reverse transcriptase SuperMix (Transgene, Beijing, China) according to the manufacturers' instructions. Further, the cDNA was employed to isolate the full-length of OSHIPP33's sequence using gene-specific primers (Table S1) and validated by sequencing. Quantitative RT-PCR was performed with a 7500 Real-Time PCR System (Applied Biosystems, Waltham, MA, USA) using SYBR Green Supermix (BIO-RAD, Hercules, CA, USA) [23].

\subsection{Subcellular Localization of OsHIPP33}

The fusion of OsHIPP33 and green fluorescent protein (GFP) genes was constructed by inserting OsHIPP33 CDS without the stop codon into a pCAMBIA1300 vector harboring the CaMV35S promoter [25]. The open reading frame of OsHIPP33 was amplified with primers adapted with KpnI and BamHI restriction sites (Table S1). The plasma membrane marker OsMADS3 and nucleus biomarker OsPIP2A fused with a red fluorescent protein (RFP) were co-introduced with OsHIPP33-GFP into the epidermal cells of tobacco (Nicotiana benthamiana) and onions (Allium cepa) using Agrobacterium tumefaciens (GV3101). GFP and RFP signals were detected by a confocal laser scanning microscopy (LSM710, Zeiss).

\subsection{Yeast Complementation Assay}

Yeast (Saccharomyces cerevisiae) wild type strain BY4741 and its mutants zrc1, ycf1, cup2, ccc1, and pmr1 displaying sensitive phenotypes under excess $\mathrm{Zn}, \mathrm{Cd}, \mathrm{Cu}, \mathrm{Fe}$, and Mn conditions were used for detoxification analysis [16]. The OsHIPP33 ORF was cloned into the expression vector pYES2 and transformed into the yeast cells, which were grown overnight to $\mathrm{OD}_{600} 0.5-0.8$ in SD-Ura liquid medium containing $2 \%$ Gal and $0.67 \%$ yeast nitrogen base. The cell suspension with serial dilutions (1:10) was spotted onto SD-Ura agar supplemented with 2, 4 and $8 \mathrm{mM} \mathrm{Zn;} \mathrm{5,} 30$ and $60 \mu \mathrm{M} \mathrm{Cd} ; 6,8$ and $10 \mathrm{mM} \mathrm{Fe;} \mathrm{2,} 4$ and $8 \mathrm{mM} \mathrm{Mn;30,60} \mathrm{and} 90 \mu \mathrm{M} \mathrm{Cu}$ in the presence of $\mathrm{Gal}$, and incubated at $30{ }^{\circ} \mathrm{C}$ for $3 \mathrm{~d}$. Agar plates without metals served as controls [18]. 


\subsection{Generation and Analysis of RNAi and Mutant Lines}

The sense and antisense 498-bp fragments of OsHIPP33 were generated using two pairs of primers (Table S1) and cloned into pCAMBIA1390-RNAi to form pCAMBIA1390OsHIPP33-RNAi construct under the control of the CaMV 35S promoter. The resultant constructs were transformed into rice callus via Agrobacterium tumefaciens to generate OsHIPP33-RNAi transgenic lines [23]. The suppression of OsHIPP33 expression was confirmed by checking its transcripts in two randomly selected OsHIPP33-RNAi transgenic lines denoted i2 and i5.

The T-DNA insertion mutant OsHIPP33 (Nipponbare background) was purchased from Kyung Hee University, Korea. Plants were confirmed for homozygosity for this allele by genotyping with specific primers (Table S1). The PCR cycling conditions were $94{ }^{\circ} \mathrm{C}$ for 5 min, followed by 35 cycles at $94{ }^{\circ} \mathrm{C}$ for $30 \mathrm{~s}, 60{ }^{\circ} \mathrm{C}$ for $30 \mathrm{~s}$, and $72{ }^{\circ} \mathrm{C}$ for 1 min, with a final extension at $72{ }^{\circ} \mathrm{C}$ for $10 \mathrm{~min}$.

\subsection{Determination of Metals}

Yeast cells were collected, centrifuged, rinsed in $10 \mu \mathrm{M}$ EGTA solution (pH 5.0 under $4{ }^{\circ} \mathrm{C}$ ) for seconds, then bathed with deionized water and freeze dried. For plant tissues, shoots and roots were separately harvested, soaked in $0.5 \mathrm{mM}$ calcium chloride solution for $30 \mathrm{~s}$, thoroughly rinsed with distilled water, and dried at $72{ }^{\circ} \mathrm{C}$ for 3 days. The dried yeast and plant samples were digested in nitric acid. The metal concentration was determined by inductively coupled plasma mass spectrometry (ICP-MS) [16].

For soil metal determination, samples of nine replicates were randomly collected from the surface layer $(20 \mathrm{~cm})$ in the rice field. The collected soil samples were manually crumbled, air-dried, and sieved through a $2 \mathrm{~mm}$ mesh to remove root residues and small rocks. The dried soil samples were microwave-digested with nitric acid and hydrogen peroxide $\left(\mathrm{HNO}_{3}: \mathrm{HClO}_{4}=1: 1, v / v\right)$ at temperature of $160{ }^{\circ} \mathrm{C}$ [24].

\subsection{Statistical Analysis}

All experiments in the study were set up in triplicates, and each treatment contained at least 18 seedlings. Statistical analyses were performed using SPSS v.22.0. The significant disparity of the treatments or genotypes between wild-type (WT) and knockout or knockdown mutant lines was assessed through variance (ANOVA), followed by Tukey's test.

\section{Results}

\subsection{Analysis of OsHIPP33 Sequence and Structure}

The whole genomic sequence of OsHIPP33 is $3465 \mathrm{bp}$ in length. Its coding sequence is $972 \mathrm{bp}$ containing three introns and four exons which are predicted to encode a polypeptide of 324 amino acids (Figure S1A). There are two conserved heavy metal-associated (HMA) domains, with typical Cys-XX-Cys metal-binding motifs in the first ring similar to ferredoxin structural folding $(\beta \alpha \beta \beta \alpha)$ (Figure S1B,C). Phylogenetic analysis of rice OsHIPP33 homologous genes revealed that its close homolog is OsHIPP32 (Figure S1D). Comparison of OsHIPP33 and OsHIPP32 sequences confirmed that both have highly conserved amino acids, particularly with two HMA domains and isoprenylated motif (CaaX) (Figure S1E).

\subsection{Expression Pattern of OsHIPP33}

The temporal and spatial expression pattern of OsHIPP33 transcripts was analyzed throughout the lifespan using qRT-PCR. OsHIPP33 showed the highest transcript abundance in Node II (Figure 1A). Root, node, basal stems and leaves show a moderate expression level at all growth and developmental stages. To understand whether OsHIPP33 responds to metals, the rice plants were treated with several metals including $\mathrm{Zn}, \mathrm{Fe}, \mathrm{Cu}$, $\mathrm{Cd}$ and $\mathrm{Mn}$ under deficient and oversupply conditions. Deprivation of $\mathrm{Cu}, \mathrm{Zn}, \mathrm{Fe}$ and Mn did not affect the expression of OsHIPP33 (Figure 1B). However, when exposed to excessive metals, OsHIPP33 expression changed. Treatment with $\mathrm{Zn}$ at 1, 5 and $10 \mathrm{mM}$ led to significant upregulation of the gene in shoots and roots, of which the top expression 
occurred at $5 \mathrm{mM}$ (Figure 1C). OsHIPP33 expression was also progressively induced under high levels of $\mathrm{Fe}$ (Figure 1D). With regard to $\mathrm{Cu}, \mathrm{Cd}$ and $\mathrm{Mn}$, only slight upregulation of OsHIPP33 was detected in rice (Figure 1E-G). These results suggest that OsHIPP33 most likely responds to $\mathrm{Zn}$ and Fe. Therefore, the following study only focused on studying the effects of $\mathrm{Zn}$ and Fe on rice growth and development.
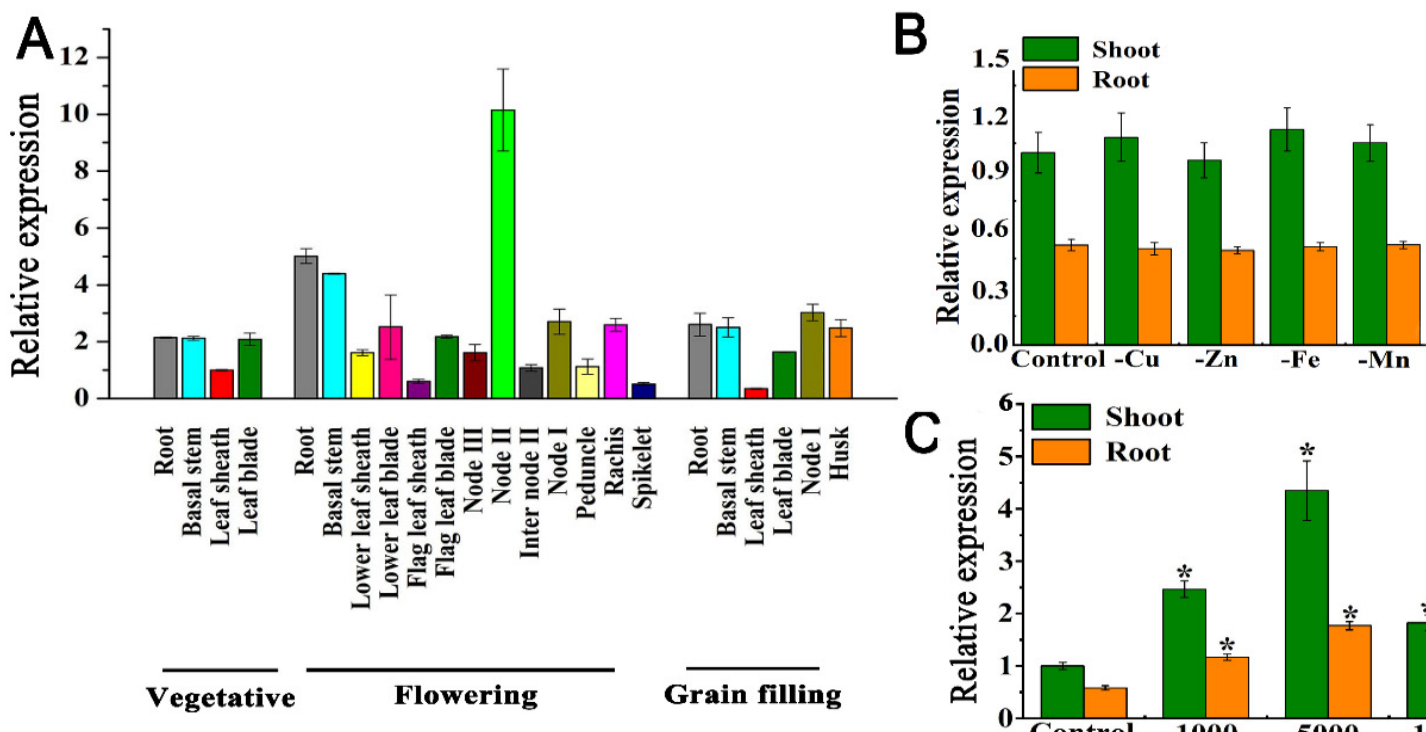

D
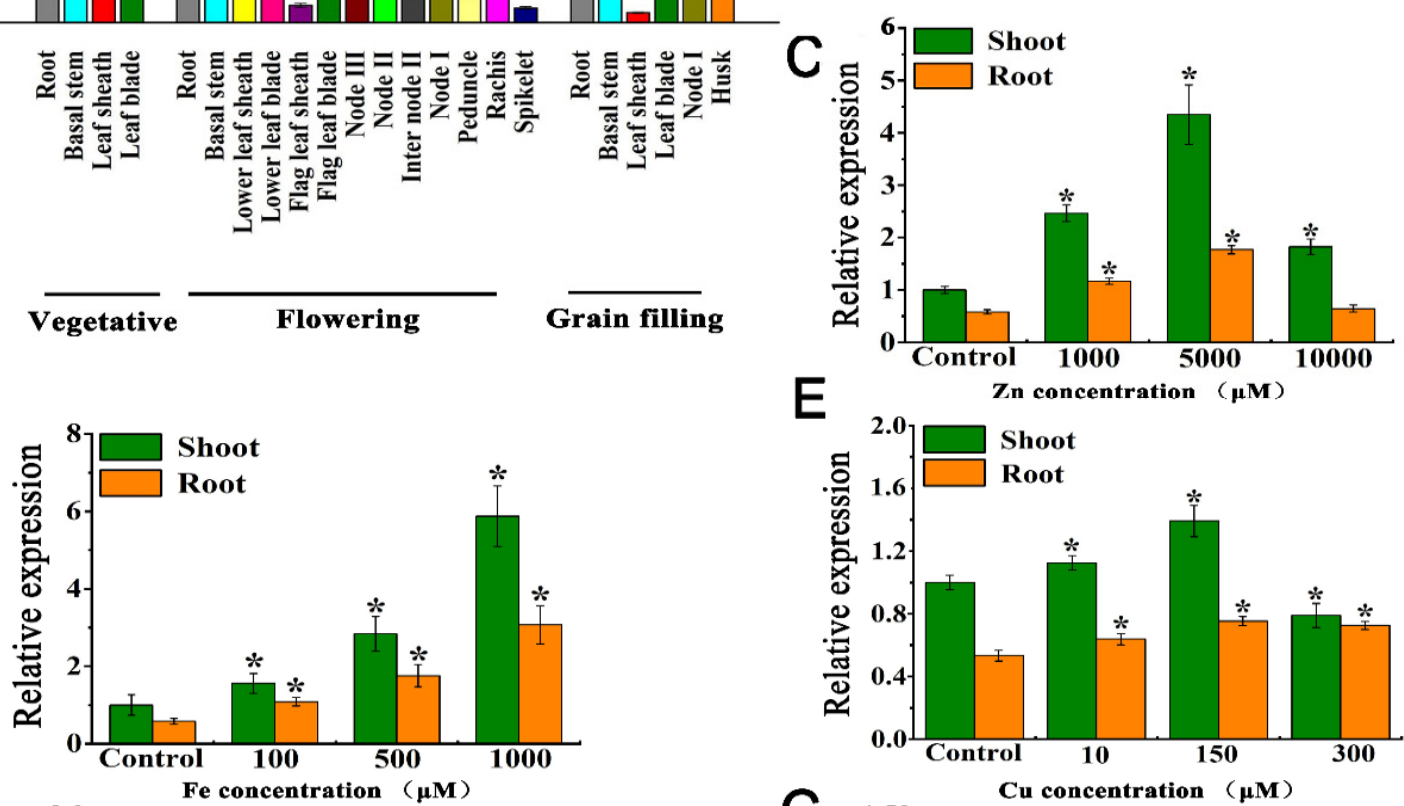

$\mathbf{F}$
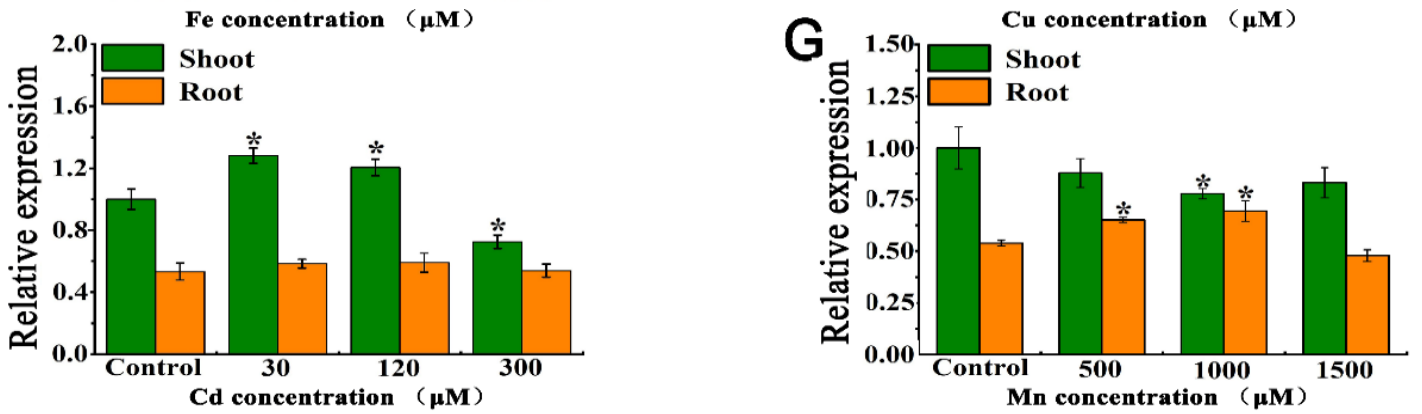

Figure 1. Transcriptional expression of OsHIPP33 in rice (Nipponbare) under normal and metal stress conditions. (A) OsHIPP33 expression in diverse tissues at different development stages. (B) Response of OsHIPP33 to metal deficiency. Ten-day-old rice was grown in a nutrient solution with (control) or without $\mathrm{Zn}, \mathrm{Fe}, \mathrm{Mn}$ or $\mathrm{Cu}$ for 2 weeks. (C-G) Two-week-old rice was grown in the nutrient solutions with 1, 5 and $10 \mathrm{mM} \mathrm{Zn;} \mathrm{0.1,} 0.5$ and $1 \mathrm{mM} \mathrm{Fe;} \mathrm{10,} 150$ and $300 \mu \mathrm{M} \mathrm{Cu} ; 30,120$ and $300 \mu \mathrm{M} \mathrm{Cd}$; and $0.5,1$ and $1.5 \mathrm{mM}$ Mn for $6 \mathrm{~h}$. Results indicate the means of biological triplicates. Asterisks indicate the significant difference between the treatments and control $(p<0.05)$.

\subsection{OsHIPP33 Is Localized to the Nucleus and Plasma Membrane}

The subcellular localization of OsHIPP33 was identified by the connection of GFP to OsHIPP33 whose expression was driven by a 35S promoter. The construct Pro35S:OsHIPP33:GFP was transiently expressed in tobacco epidermal leaves. The green fluorescence of Os- 
HIPP33:GFP was co-expressed with the nucleus (OsMADS3-RFP) and plasma membrane (PIP2A-RFP) markers (fused with mRFP). The overlapping and color changed fluorescence was visualized (Figure 2A-F). To double confirm the location, the OsHIPP33-GFP fusion vector was further transferred into the onion epidermal cells. The green fluorescence was also clearly detected in the nucleus and cell membrane of onion cells (Figure 2G-L). Together, these observations indicate that OsHIPP33 is located in the nucleus and plasma membrane but cannot be avoided in the cytoplasm as well.

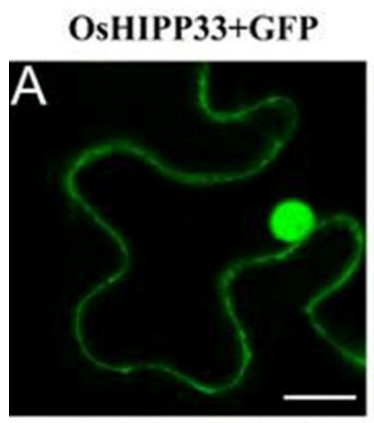

OsHIPP33+GFP

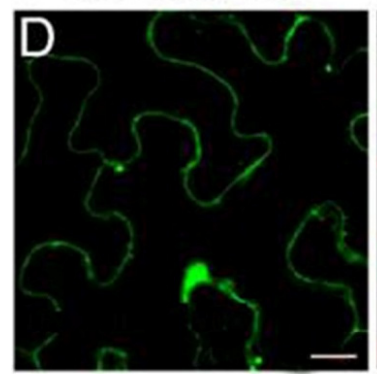

Bright field
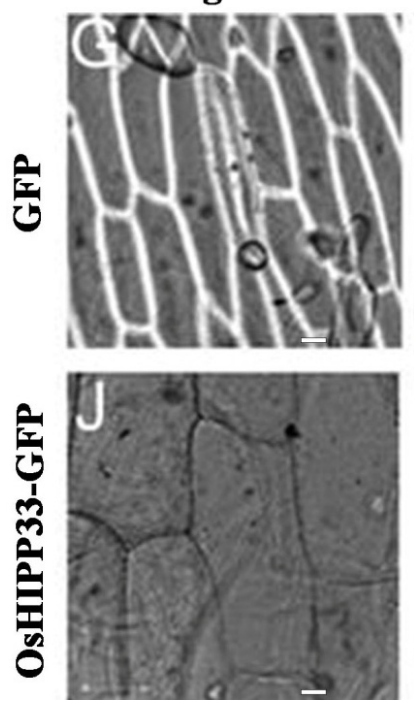

OSMADS3-RFP

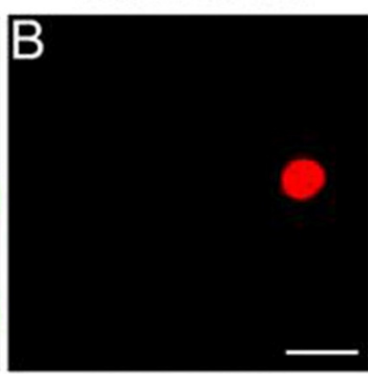

PIP2A-RFP

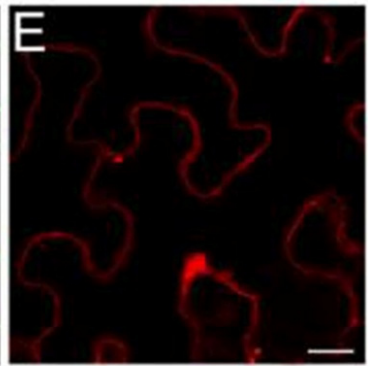

GFP
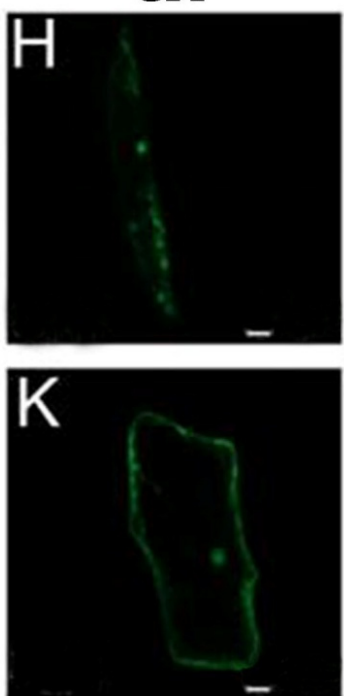

Merged

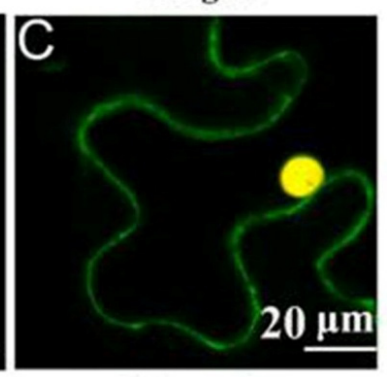

Merged

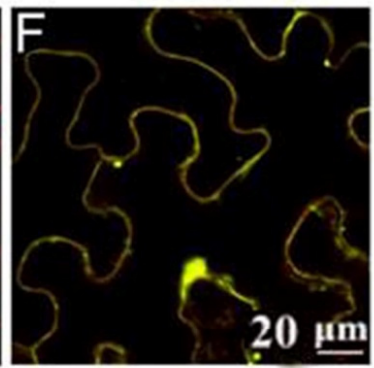

Merged
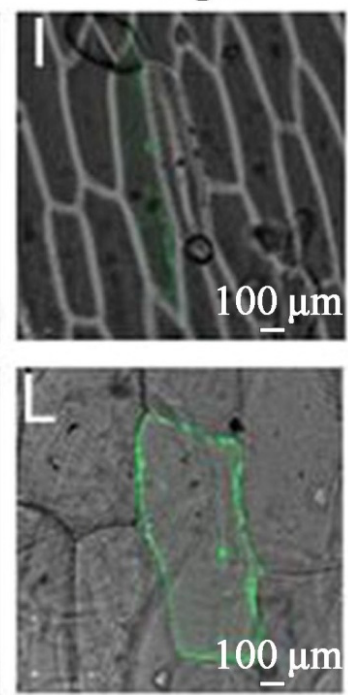

Figure 2. Subcellular localization of OsHIPP33. (A-F) Tobacco subcellular localization. (A,D) Green fluorescence of OsHIPP33-GFP fusion protein. (B) The red fluorescence of nuclear maker (OsMADS3). (C) The green fluorescence of the OsHIPP33-GFP fusion protein coincides with the red fluorescence of the nuclear maker (OsMADS3). (E) The red fluorescence of cell membrane maker (PIP2A). (F) The green fluorescence of OsHIPP33-GFP fusion protein coincides with the red fluorescence of cell membrane maker (PIP2A). (G-L) Detection of onion subcellular localization. (G,J) Bright field. (H) The fluorescence of GFP. (I) Merged between bright field and GFP fluorescence. (K) Fluorescence of OsHIPP33-GFP fusion protein. (L) The merger of OsHIPP33-GFP fusion protein fluorescence and bright field. 


\subsection{Expression of OsHIPP33 Led to Zn Accumulation in Yeast Cells}

To explore whether OsHIPP33 has metal detoxification activity, we first identified the transformants by expressing OsHIPP33 into the yeast strains defective in metal transport or detoxification. When OsHIPP33 was transformed into a zinc-sensitive mutant $(\Delta z r c)$ [16], its growth appeared better than that of pYES2 (empty vector as a control) mutants, especially under excessive zinc treatment $(8 \mathrm{mM})$ (Figure S2A). We then transferred OsHIPP33 into cadmium-sensitive $(\Delta y c f 1)$, copper-sensitive $(\Delta c u p 2)$, iron-sensitive $(\Delta c c c 1)$ and manganesesensitive $(\Delta p m r 1)$ mutant lines, and found that there was no significant difference in cell growth treated with the indicated concentrations of $\mathrm{Cd}, \mathrm{Cu}, \mathrm{Fe}$ and $\mathrm{Mn}$ (Figure S2B-E). The metal concentrations were determined in the cells expressing OsHIPP33 but no significant disparity from controls was detected under $\mathrm{Zn}, \mathrm{Cd}, \mathrm{Cu}, \mathrm{Fe}$ and $\mathrm{Mn}$ treatments (Figure S3).

3.5. OsHIPP33 Did Not Functionally Regulate Rice Growth and Zn and Fe Accumulation during the Early Vegetative Stage

We attempted to identify the biological function of OsHIPP33 in the mediation of rice growth and metal accumulation at the early stage. To perform the study, a T-DNA insertion mutant and RNAi lines were acquired. The T-DNA insertion into OsHIPP33 was confirmed by PCR (Figure S4). Meanwhile, twenty-four independent OsHIPP33 knockdown mutant lines (T3 generation) were generated by RNA interference (RNAi). Two of the homozygous lines RNAi-2 (i2) and RNAi-5 (i5) were randomly selected in use for the study. Their transcriptional expression was down-regulated by $47 \%$ and $55 \%$, respectively (Figure S4C). Since the rice undergoes early vegetative growth for about one month, we thus performed a short term hydroponic experiment with rice growing under conditions of normal $\mathrm{Zn}, \mathrm{Fe}$, $\mathrm{Cu}$ and $\mathrm{Mn}$ supply. Following a four-week-long growth period, the rice seedlings did not show variations of shoot elongation and biomass between the wild-type and OsHIPP33 mutant or RNAi lines, except the roots in which the knockdown and knockout of OsHIPP33 led to a slightly significant reduction of root elongation (Figure S5). The same response was true for the accumulation of $\mathrm{Zn}, \mathrm{Fe}, \mathrm{Cu}$ and $\mathrm{Mn}$ in plants (Figure S6). These results indicate that OsHIPP33 might not work at the early vegetative stage.

\subsection{Mutation of OsHIPP33 Compromised Growth and Reproductivity of Rice}

To understand the functional role of OsHIPP33 in rice, we performed a two-year field experiment on the knockout and knockdown mutant lines under natural conditions. The local agronomic practice was adopted to manage rice cropping throughout the lifespan. Dominant agronomic traits such as yield constituent and grain yield were surveyed. The significant disparity in plant height between OsHIPP33 or RNAi2/5 and wild-type was identified at the mature stage (Figure 3A). The plant height of OsHIPP33, RNAi-2 and RNAi-5 decreased by $21 \%, 11 \%$ and $11 \%$ respectively, compared with WT (Figure 3B). We specified the measures relevant to the grain yield. All leaf sheaths of the plants were removed and the internodes were kept for analysis (Figure 3C). The length of internode III, IV, and V of the OsHIPP33 plants decreased by $45 \%, 38 \%$, and $41 \%$, respectively, relative to the wild-type (Figure 3D). A similar trend was observed for the two RNAi lines, indicating that knockout or knockdown of OsHIPP33 impaired the rice apical dominance.

We further counted the number of tillers and effective panicles and found that the tillers of OsHIPP33 and RNAi- 5 declined by $23 \%$ and $16 \%$, respectively (Figure $3 \mathrm{E}$ ). The number of effective panicles was reduced by $35 \%$ and $26 \%$, respectively for OsHIPP33 and RNAi-2 (Figure 3F). Although no significant variations in the tillers and effective panicles between RNAi-2 or RNAi-5 and wild-type were detected, knocking down OsHIPP33 indeed repressed the agronomic phenotypes. 

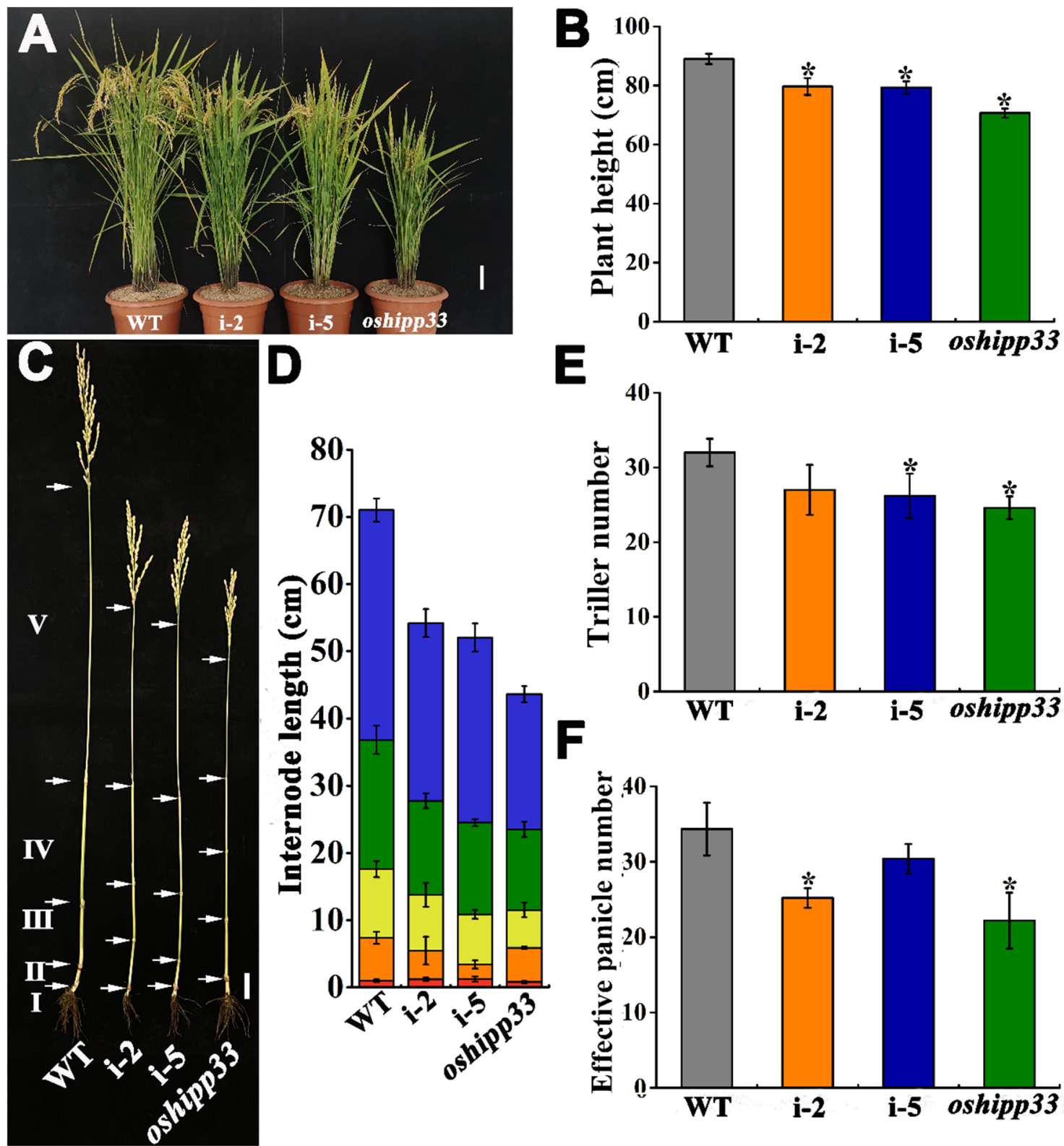

Figure 3. Morphological differences between OsHIPP33 mutant, RNAi (i-2 and i-5) lines and wildtype (WT) at the maturity stage. The rice varieties were grown in the field under natural conditions for two successive year trials. (A) The phenotypes of WT, RNAi and OsHIPP33 (scale bars: $10 \mathrm{~cm}$ ). (B) Plant height comparison of WT, RNAi and OsHIPP33. (C) Stem structure of WT, RNAi and OsHIPP33. The interval between the two arrows shows the length of internode (scale bars: $3 \mathrm{~cm}$ ). (D) Internode length comparison of WT, RNAi and OsHIPP33. (E) Comparison of tiller number per plant between WT, RNAi and OsHIPP33. (F) Effective panicle number per plant comparison between WT, RNAi and OsHIPP33. The vertical bars indicate the means of biological triplicates and asterisks show the significant difference between the mutant lines and WT $(p<0.05)$.

Further specific analysis of seed phenotypes and reproductivity revealed that the panicle length of OsHIPP33 and two RNAi lines and the grain yield per plant were significantly lower than those of wild-type (Figure 4A). The panicle lengths of OsHIPP33, RNAi-2 and RNAi- 5 were shortened by $20 \%, 13 \%$ and $12 \%$, respectively compared with those of wild-type (Figure 4B). Analysis of the length and width of seeds showed no significant disparity of seed width between all mutant lines and wild-type, but only the length of OsHIPP33 plants appeared significantly shorter than that of wild-type (Figure 4C-F). The 
grain yields of OsHIPP33, RNAi-2 and RNAi-5 were $63 \%, 41 \%$ and $31 \%$ less than the wild-type (Figure $4 \mathrm{G}, \mathrm{H}$ ). Comparative analyses of seed fertility signified that the fertility rates of OsHIPP33, RNAi-2 and RNAi- 5 lines declined by $47 \%, 22 \%$ and $28 \%$, respectively (Figure 4I). For 1000-grain weight, there were 18\%, 9\% and 9\% reductions for OsHIPP33, RNAi-2 and RNAi-5, respectively (Figure 4J). The yield per square meter had a downside by about $52 \%, 15 \%$ and $12 \%$ for OsHIPP33, RNAi-2 and RNAi-5 lines (Figure $4 \mathrm{~K}$ ). Overall, OsHIPP33 knockout or knockdown indeed sabotaged the panicle elongation, seed fertility and grain development, which consequently reduced the grain yield.
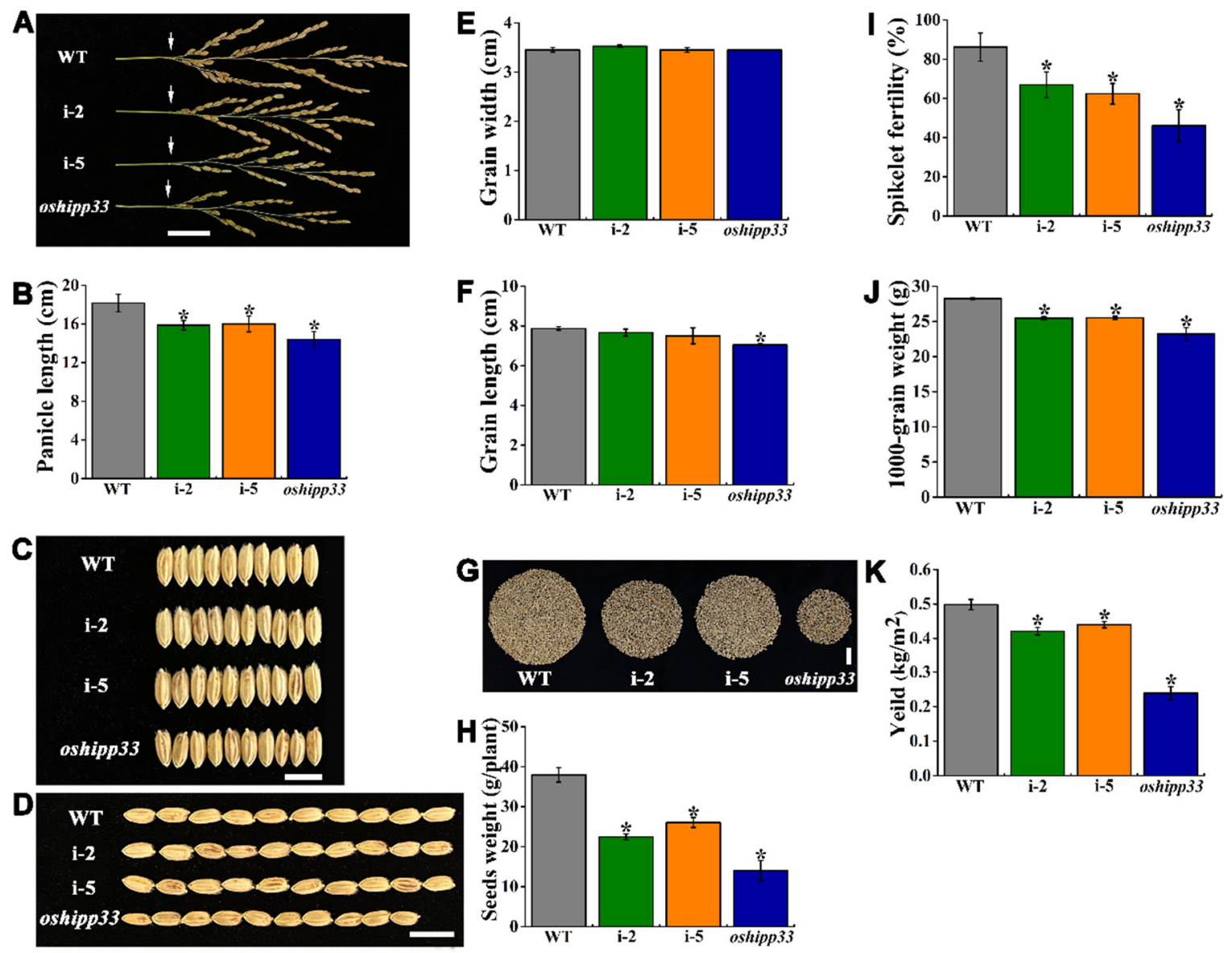

Figure 4. OsHIPP33 knockout (OsHIPP33 mutant) and knockdown (RNAi, i-2 and i-5) lines developed the shortened panicle size and reduced grain yield. The rice varieties were grown in the field under natural conditions for two successive year trials. (A) Phenotypes of panicle (scale bars: $3 \mathrm{~cm}$ ) and (B) panicle length. (C-F) Phenotypes of seed size (scale bars: $1 \mathrm{~cm}$ ). (G) Total seeds collected (Scale bars: $3 \mathrm{~cm}$ ) and $(\mathbf{H})$ seed weight from one plant. (I) Spikelet fertility of one panicle and (J) 1000-grain weight. (K) Seed yield per square meter. The vertical bars indicate the means of biological triplicates and the asterisks show significant differences between the mutant lines and WT $(p<0.05)$.

\subsection{Mutation of OsHIPP33 Reduced Zn and Fe Concentrations in Rice Tissue}

The metal concentrations were quantified using the rice tissues (the above-ground straw, husk and brown rice) sampled at the mature stage. The concentrations of $\mathrm{Zn}$ and Fe in the straw were significantly reduced. Zinc concentrations in husk and brown rice show no difference except for the husk in OsHIPP33, where the Zn concentration was slightly but significantly lower than that of wild-type (Figure 5A). Determination of Fe accumulation revealed a drastic reduction in the tissues, particularly in the husk and brown rice (Figure 5B). These results indicate that disruption of OsHIPP33 led to reduced accumulation of $\mathrm{Fe}$ or $\mathrm{Zn}$ in the rice tissues. 


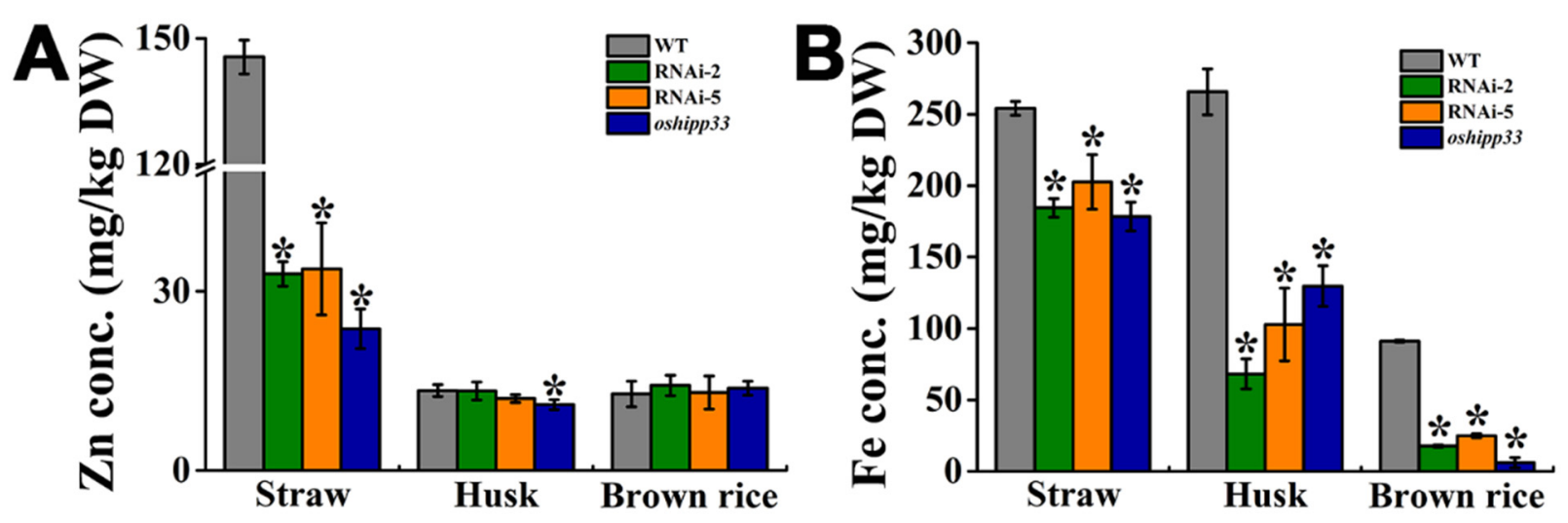

Figure 5. Zn and Fe concentrations in different rice tissues at maturity stage of OsHIPP33 mutant, RNAi lines and wild-type (WT). The rice varieties were grown in a field under natural conditions for two successive year trials. (A) Zn concentration. (B) Fe concentration. The vertical bars indicate the means of biological triplicates and the asterisks show the significant difference between the mutant lines and WT $(p<0.05)$.

\subsection{OsHIPP33 and RNAi Lines Are Sensitive to Excessive Zn and Fe Stress and Accumulated More Metals}

Recent studies have shown that some rice HIPP genes can detoxify the metals at the higher noxious level $[18,19]$. This prompted us to investigate whether OsHIPP33 plants had a similar effect on plant responses to excessive $\mathrm{Zn}$ and Fe. Two-week-old rice seedlings were treated with $0.4 \mu \mathrm{M}$ (normal) and $500 \mu \mathrm{M}$ Zn (excess) or $20 \mu \mathrm{M}$ (normal) and $1000 \mu \mathrm{M}$ Fe (excess) for two weeks. No significant difference was observed in the growth of the mutant lines and wild-type under normal conditions. However, the OsHIPP33 and RNAi lines showed reduced growth phenotypes under the metal stress (Figure 6). For example, the shoot length of the OsHIPP33 and two RNAi lines under Fe stress decreased by 19\% and 15-17\%, respectively, compared with the WT (Figure S7C). Further biomass assessment revealed that the shoot dry weight of the OsHIPP33 line was 33\% lower than that of the WT, and the RNAi lines also decreased by $28-30 \%$ (Figure 6E). These results suggest that the repression of OsHIPP33 could be responsible for the reduced growth under $\mathrm{Zn}$ and Fe excess.

We further measured the $\mathrm{Zn}$ and Fe concentrations in the tissues in the plants. Analyses showed that accumulation of $\mathrm{Zn}$ and Fe in the root and shoot of the OsHIPP33 mutant and RNAi lines were higher than WT with oversupply of Zn and Fe (Figure 7), except RNAi-2 where the increased Fe concentration in the root was not statistically evident. This result indicates that over-accumulation of $\mathrm{Zn}$ and Fe in the OsHIPP33 and RNAi lines would be the cause of the stunted growth of rice. 

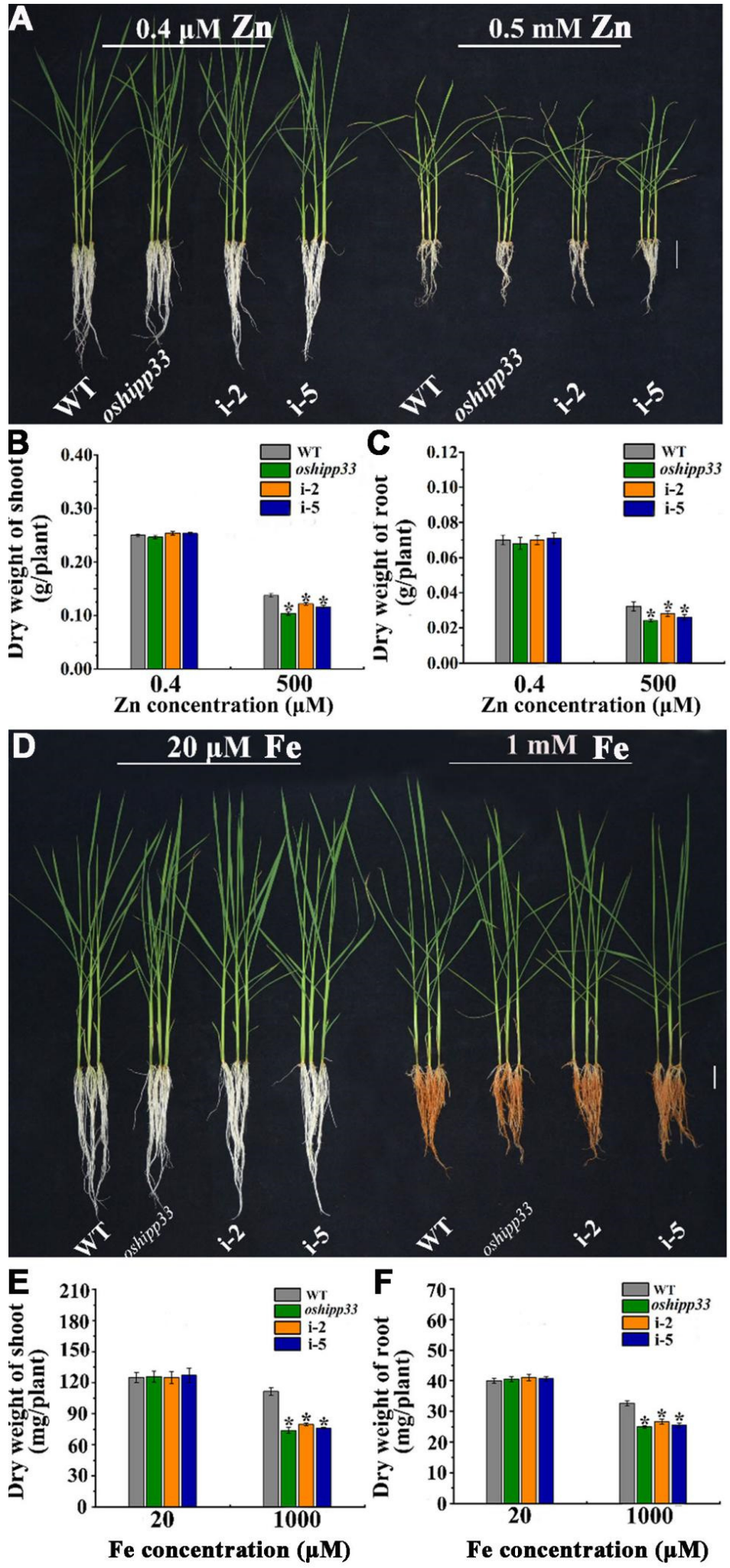

Figure 6. Growth phenotypes of OsHIPP33 mutant, RNAi lines (i-2 and i-5) and wild-type (WT) under excessive $\mathrm{Zn}$ and Fe stress. Two-week-old rice seedlings were exposed to the nutrient solution containing $0.4 \mu \mathrm{M}$ Zn (normal) and $500 \mu \mathrm{M}$ Zn (excess) (A-C) or $20 \mu \mathrm{M}$ Fe (normal) and $1000 \mu \mathrm{M} \mathrm{Fe}$ (excess) (D-F) for two weeks. When harvested, the rice plants were photographed and phenotypically analyzed. The dry weight of shoot and root of the plants under excess Zn and Fe was estimated. Scale bars: $3 \mathrm{~cm}$ for $(\mathbf{A}, \mathbf{D})$. The vertical bars indicate the means of biological triplicates and the asterisks show the significant difference between the mutant lines and WT $(p<0.05)$. 

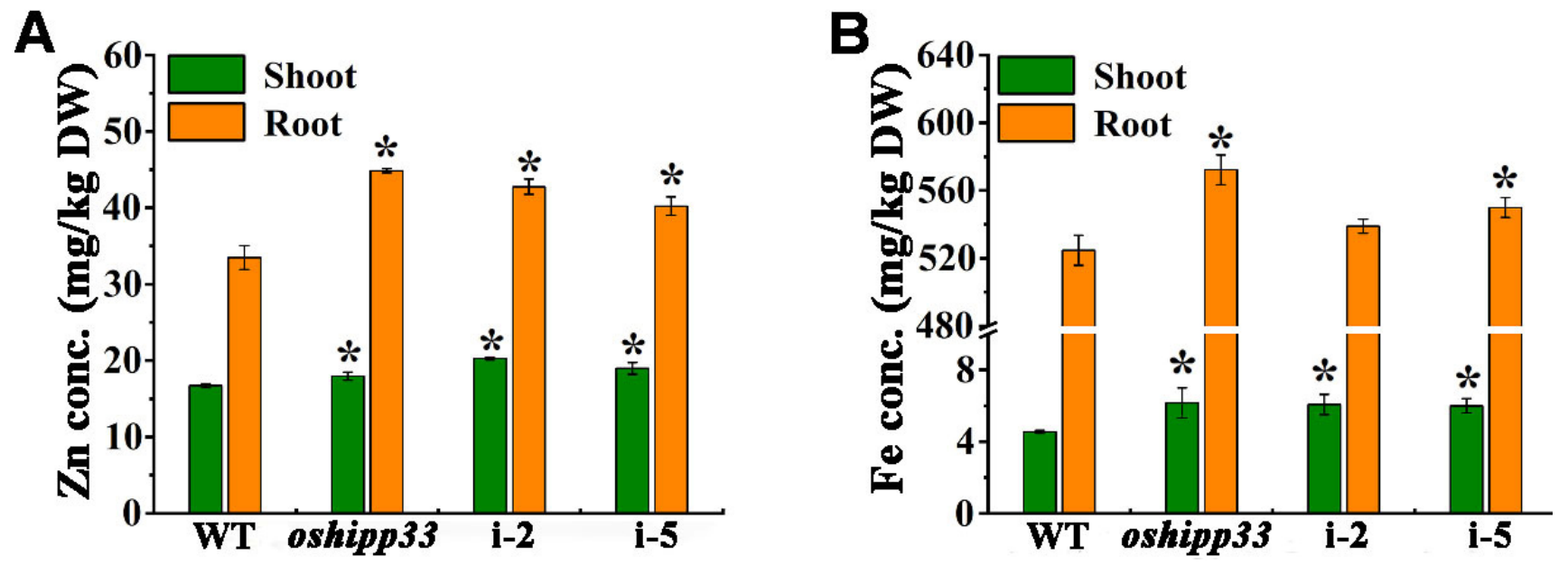

Figure 7. Analysis of $\mathrm{Zn}$ and Fe concentrations in OsHIPP33 mutant, RNAi lines and wild-type (WT) treated with excess Zn and Fe. (A) Zn concentrations in shoot and root with $500 \mu \mathrm{M}$ Zn supply. (B) Fe concentrations in shoot and root with $1000 \mu \mathrm{M}$ Fe supply. The vertical line indicates the error bar and the asterisks indicate a significant difference between the mutant lines and WT $(p<0.05)$.

\section{Discussion}

$\mathrm{Zn}$ and Fe are essential microelements for all organisms required for many biological processes; however, the abundance of $\mathrm{Zn}$ and Fe in plants must be under tight control [4]. Either deficiency or excess of the metal ions leads to dysfunctions of plant physiological, biochemical and molecular processes. For example, overload of Fe ions triggers oxidative stress response [26]. Previous studies have demonstrated that several HIPP metallochaperones respond to metal stress and in turn mediate the metal stress response $[16,19,27,28]$, but how these HIPPs regulate the levels of $\mathrm{Zn}$ and Fe to attain homeostasis is not fully understood. This study characterized the rice locus encoding OsHIPP33 and presented it's critical role in regulating rice growth, grain yield, and $\mathrm{Zn}$ and Fe accumulation. These results allow us to conclude that OsHIPP33 at least required for $\mathrm{Zn}$ and Fe accumulation and homeostasis in rice plants [29-32].

\subsection{OsHIPP33-Mediated Zn and Fe Accumulation Is Responsible for Rice Grain Yield}

Subcellular and tissue expression shows that OsHIPP33 was targeted to the nucleus/cytoplasm and expressed in diverse organs throughout the development stages, especially at the flowering and mature phases (Figure 1), suggesting that OsHIPP33 would play roles in fertility and seed development. Simultaneously, OsHIPP33 expression in root, basal stem, nodes I-II as well as the above-ground lower leaves, sheath and grains implied that OsHIPP33 is likely involved in $\mathrm{Zn}$ or Fe long-distance transport through the vascular bundles between root and shoot tissues. Many genes mediating rice architecture and reproductivity, particularly for those master genes controlling plant height, panicle phenotype and grain size and yield, have been identified [33-35]. The concentration of $\mathrm{Zn}$ in rice is associated with plant growth and development [1]. OsmiR156, for example, guides OsSPL14 in maintaining an ideal plant architecture of rice under a suitable mineral supply [36]. The high concentration of $\mathrm{Zn}$ in rice vegetative organs or tissues is likely associated with the $\mathrm{Zn}$ concentration in grains, but depends more on the $\mathrm{Zn}$ distribution mediated by some $\mathrm{Zn}$ transporters such as OsZIP4, which can transport $\mathrm{Zn}$ to the phloem nodes and further to tiller buds and panicles [37]. However, knowledge of the functional role of HIPP proteins during rice development is stringently rare. Recently, a study with HIPP24 in rice shows that OsHIPP24 knockout or overexpression in rice resulted in suppressed growth response without any relevance to the concentration of $\mathrm{Cu}$ supply [38]. Different to this, the OsHIPP33 knockout or knockdown led to attenuated growth phenotypes with decreased plant height, number of tillers and panicles, and spikelet fertility rate, all of 
which determine the grain yield of rice. Furthermore, the OsHIPP33 mutants recorded a lower degree of $\mathrm{Zn}$ and Fe accumulation in brown rice grains and husks. The reduction of grain yield in the mutant lines was most likely associated with the deficiency of $\mathrm{Zn}$ and Fe (Figure 5). The $\mathrm{Zn}$ deficiency was reported to compromise plant development with specific symptoms such as smaller leaf size and short internodes, which ultimately reduce grain production [7], while the enhanced level of $\mathrm{Zn}$ in rice contributes to the number and growth of tillers [39]. The possible mechanism for the physiological response can be linked to the phytohormone auxin [34]. Supportive evidence comes from the study with 2,4-D (an auxin-like plant regulator) and $\mathrm{Zn}$ treatment of rice that activated the elongation factor-1beta required for auxin- and zinc-induced root formation and as a result promoted the enhancement of plant growth and development [40]. A recent study demonstrates that cytokinins are actively involved in the grain filling of rice under alternate wetting and drying irrigation [41]. Moreover, the cytokinin metabolism was reported to be regulated by Zn availability in a complicated dynamic way, suggesting that the cytokinin-dependent signaling pathway covers the maintenance of zinc nutrition in rice [42]. Interestingly, a small group of Arabidopsis HIPP proteins (AtHIPP1 and AtHIPP6) was reported to regulate the abundance of cytokinin by a specific interaction with cytokinin-degrading CKX proteins which are subjected to endoplasmic reticulum-associated degradation for plant development. This demonstrates that manipulation of levels of the HIPP protein may be associated with cytokinin synthesis and morphological responses in the cytokinin signaling pathway [43]. These lines of evidence along with our observations in this study suggest that loss of OsHIPP33 function could be the result of $\mathrm{Zn}$ and Fe deficiency or imbalance in rice plants.

\subsection{OsHIPP33 Maintains Homeostasis under Excessive Zn/Fe Stress}

In this research, OsHIPP33 was found to be induced by excessive $\mathrm{Zn}$, Fe and Cu stress, but the yeast complementation experiment revealed that only $\mathrm{Zn}$ could be detoxified in the OsHIPP33-transformed cells (Figure S2). Previous studies show that when excess metals such as Cd enter plants, they can be chelated by HIPP proteins $[18,28]$. OsHIPP29, for example, maintains intracellular ion homeostasis under excessive $\mathrm{Zn}$ stress to prevent cellular toxicity [19]. In this study, OsHIPP33 and RNAi lines were subjected to excessive Zn and $\mathrm{Fe}$, the results of which show that these mutant lines were more vulnerable to the toxicity of overloaded $\mathrm{Zn}$ and Fe. Measurement of $\mathrm{Zn}$ and Fe concentrations revealed that the two metals in the OsHIPP33 and RNAi lines were over-accumulated, suggesting that disruption of OsHIPP33 could dampen the capacity of homeostasis of $\mathrm{Zn}$ and Fe. The cytosolic $\mathrm{Zn}$ and Fe ions should be maintained at relatively low optimal concentrations, while extra metal ions must be chelated or sequestrated as non-toxic forms in the vacuole [44]. The tonoplast transporters OsOZT1 and OsMTP1 dispatch excess Zn inside the vacuoles for prevention of toxicity [45,46]. Ferritin stores about $4000 \mathrm{Fe}$ atoms [47] and the rice ferritin genes OsFER1 and OsFER2 function against excess Fe accumulation [48]. Ferric reductase oxidase (FRO), an enzyme that reduces $\mathrm{Fe}^{3+}$ to $\mathrm{Fe}^{2+}$ for absorption in strategy I plants, is also shown to maintain Fe homeostasis in rice; knockdown of OsFRO1 improves Fe resistance, whereas its overexpression enhances Fe availability in the cytoplasm, making it more sensitive to Fe toxicity in the transgenic lines [49]. Whether and how OsHIPP33 would mediate $\mathrm{Zn}$ and Fe accumulation remains to be investigated. Taken together, this study has reported the identification of OsHIPP33 as a novel component for $\mathrm{Zn}$ and Fe homeostasis in rice. Disrupting OsHIPP33 by RNA interference and knockout compromised rice growth, biomass, and many other agronomic traits, with an overall lower level of $\mathrm{Zn}$ and Fe accumulation in plants. From these results, it can be concluded that OsHIPP33 is required for proper $\mathrm{Zn}$ and Fe accumulation as well as healthy plant and seed development. 
Supplementary Materials: The following are available online at https:/ / www.mdpi.com/article/ 10.3390/agronomy12020488/s1, Figure S1: Basic information of OsHIPP33 gene and protein structures. (A) Diagram of the OsHIPP33 gene structure. (B) Predicted HMA domains of OsHIPP33 by Simple Modular Architecture Research Tool (SMART, http:/ / smart.embl-heidelberg.de). (C) Threedimensional structure of OsHIPP33. (D) Phylogenetic analysis of OsHIPP33 homologous genes in rice. The numbers at branching sites indicate the posterior probability values for nodal support. The sequences of rice genes are from rice genome database (http:/ / rice.plantbiology.msu.edu). The red triangles indicate OsHIPP33. (E) Alignment of amino acid sequences for OsHIPP33 (LOC_Os02g30650.1) and OsHIPP32 (LOC_Os07g20340.1). The red rectangle represents two HMA domains and CaaX notif. The neighbor-joining phylogenetic tree was constructed using MEGA 6.0. Sequence alignment was performed by DNAMAN; Figure S2: Transport activity of OsHIPP33 in yeast. Yeast strains BY4741, $\Delta y c f 1, \Delta c u p 2, \Delta c c c 2$ and $\Delta p m r 1$ transformed with empty vector pYES2 (Vector) or OsHIPP33 were cultivated on varied concentrations of $\mathrm{Cd}, \mathrm{Cu}, \mathrm{Fe}$ and $\mathrm{Mn}$ as indicated. Eight microliters of cell suspension with an OD $600 \mathrm{~nm}$ of 0.5 and four serial 1:10 dilutions were spotted and incubated at $30{ }^{\circ} \mathrm{C}$ for $3 \mathrm{~d}$; Figure S3: The metal concentrations in the yeast cells after OsHIPP33 transformation. $\mathrm{Zn}, \mathrm{Cd}, \mathrm{Cu}, \mathrm{Fe}$, and $\mathrm{Mn}$ were absorbed by cells in the liquid medium. The yeast BY4741 and zrc1, ycf1, cup2, ccc1 and pmr1 carrying pYES2 or with pYES2 vectors containing the full OsHIPP33 cDNA were cultured in a liquid medium containing $2 \%$ Gal in the presence of $200 \mu \mathrm{M} \mathrm{Zn}, 5 \mu \mathrm{M} \mathrm{Cd}, 10 \mu \mathrm{M} \mathrm{Cu}$, $2 \mathrm{mM} \mathrm{Fe}$, and $2 \mathrm{Mm} \mathrm{Mn}$ for $48 \mathrm{~h}$, respectively. The metal concentration in the yeast was determined with ICP-MS after digestion. Data are means of three biological replicates; Figure S4: Analysis of OsHIPP33 transcriptional expression in the mutant lines by qRT-PCR. (A) Schematic diagram of OsHIPP33 mutant insertion sites. The triangle indicates the insertion site of the T-DNA. LP and RP are the primers on the genome near the insertion site. RB is the universal identification primer on the T-DNA. The white square boxes are the UTR region. The black square boxes are exons, and the black lines are introns. (B) Homogeneous identification of OsHIPP33 mutants. (C) qRT-PCR analyses of OsHIPP33 transcripts in the two RNAi lines. The vertical bars indicate the means of biological triplicates. Asterisks show a significant difference between the mutants and WT $(p<0.05)$; Figure S5: Growth phenotypes of OsHIPP33 mutant, RNAi lines and wild-type under the normal $\mathrm{Zn}, \mathrm{Fe}, \mathrm{Cu}$ and Mn supply conditions. The germination rice seedlings were grown in the nutrient solution with the normal metals as mineral nutrients $(0.4 \mu \mathrm{M} \mathrm{Zn}, 20 \mu \mathrm{M} \mathrm{Fe}, 0.2 \mu \mathrm{M} \mathrm{Cu}$ and $0.5 \mu \mathrm{M} \mathrm{Mn})$ for four weeks. The rice plants were photographed. A: Growth phenotypes, B: the shoot and root length and C: dry weight of OsHIPP33 mutant and RNAi lines (scale bars: $3 \mathrm{~cm}$ ). The vertical bars indicate the means of biological triplicates. Asterisks show a significant difference between the mutants and WT $(p<0.05)$; Figure S6: The concentrations of $\mathrm{Zn}, \mathrm{Fe}, \mathrm{Cu}$ and $\mathrm{Mn}$ in shoots and roots of OsHIPP33 mutant, RNAi (i2 and i5) lines and wild-type (WT) under the normal conditions of $\mathrm{Zn}, \mathrm{Fe}, \mathrm{Cu}$ and Mn supply. The germination rice seedlings were grown in the nutrient solution with the normal metals as mineral nutrients $(0.4 \mu \mathrm{M} \mathrm{Zn}, 20 \mu \mathrm{M} \mathrm{Fe}, 0.2 \mu \mathrm{M} \mathrm{Cu}$ and $0.5 \mu \mathrm{M} \mathrm{Mn})$ for four weeks. (A-D) $\mathrm{Zn}, \mathrm{Fe}, \mathrm{Cu}$ and $\mathrm{Mn}$ concentrations analyzed in WT and OsHIPP33 mutants and RNAi lines. The vertical bars indicate the means of biological triplicates; Figure S7: Growth phenotypes of OsHIPP33 mutant, RNAi lines and wild-type (WT) under excessive $\mathrm{Zn}$ and Fe stress. Two-week-old seedlings were exposed to the nutrient solution containing $0.4 \mu \mathrm{M} Z \mathrm{Zn}$ (normal) and $500 \mu \mathrm{M} \mathrm{Zn} \mathrm{(excess)} \mathrm{(A,} \mathrm{B)} \mathrm{or} 20 \mu \mathrm{M} \mathrm{Fe}$ (normal) and $1000 \mu \mathrm{M}$ Fe (excess) (C, D) for two weeks. When harvested, the rice plants were photographed and phenotypically analyzed with shoot and root length. The vertical bars indicate the means of biological triplicates. Asterisks show a significant difference between the mutants and WT $(p<0.05)$; Table S1: Primer sequences used for this study.

Author Contributions: H.W.C., C.L., B.Q.Z. and J.K.R. were responsible for the investigation, methodology, conceptualization, validation, visualization and data analysis. Z.M.Y.: worked for project administration, resources, supervision, original draft, review \& editing. All authors have read and agreed to the published version of the manuscript.

Funding: Not applicable.

Institutional Review Board Statement: Not applicable.

Informed Consent Statement: Not applicable.

Data Availability Statement: Not applicable.

Conflicts of Interest: The authors declare no conflict of interest. 


\section{References}

1. Marschner, H. Marschner's Mineral Nutrition of Higher Plants; Academic Press: New York, NY, USA, 2011.

2. Wessells, K.R.; Brown, K.H. Estimating the global prevalence of zinc deficiency: Results based on zinc availability in national food supplies and the prevalence of stunting. PLoS ONE 2012, 7, e50568. [CrossRef]

3. Burchi, F.; Fanzo, J.; Frison, E. The role of food and nutrition system approaches in tackling hidden hunger. Int. J. Environ. Res. Public Health 2011, 8, 358-373. [CrossRef] [PubMed]

4. Amare, K.; Zeleke, H.; Bultosa, G. Variability for yield, yield related traits and association among traits of sorghum (Sorghum Bicolor (L.) Moench) varieties in Wollo, Ethiopia. J. Plant Breed. Crop Sci. 2015, 7, 125-133.

5. Kobayashi, T.; Nishizawa, N.K. Iron uptake, translocation, and regulation in higher plants. Annu. Rev. Plant Biol. 2012, 63, 131-152. [CrossRef] [PubMed]

6. Briat, J.F.; Dubos, C.; Gaymard, F. Iron nutrition, biomass production, and plant product quality. Trends Plant Sci. 2015, 20, 33-40. [CrossRef] [PubMed]

7. Bashir, K.; Ishimaru, Y.; Nishizawa, N.K. Molecular mechanisms of zinc uptake and translocation in rice. Plant Soil 2012, 361, 189-201. [CrossRef]

8. Takahashi, R.; Ishimaru, Y.; Shimo, H.; Ogo, Y.; Senoura, T.; Nishizawa, N.K.; Nakanishi, H. The OsHMA2 transporter is involved in root-to-shoot translocation of Zn and Cd in rice. Plant Cell Environ. 2012, 35, 1948-1957. [CrossRef]

9. Vatansever, R.; Filiz, E.; Eroglu, S. Genome-wide exploration of metal tolerance protein (MTP) genes in common wheat (Triticum aestivum): Insights into metal homeostasis and biofortification. Biometals 2017, 30, 217-235. [CrossRef]

10. Eide, D.; Broderius, M.; Fett, J.; Guerinot, M.L. A novel iron-regulated metal transporter from plants identified by functional expression in yeast. Proc. Natl. Acad. Sci. USA 1996, 93, 5624-5628. [CrossRef]

11. Nozoye, T.; Nagasaka, S.; Kobayashi, T.; Takahashi, M.; Sato, Y.; Sato, Y.; Uozumi, N.; Nakanishi, H.; Nishizawa, N.K. Phytosiderophore efflux transporters are crucial for iron acquisition in graminaceous plants. J. Biol. Chem. 2011, 286, 5446-5454. [CrossRef]

12. Kavitha, P.G.; Kruvilla, S.; Mathew, M.K. Functional characterization of a transition metal iron transporter OsZIP6 from rice Oryza sativa L. Plant Physiol. Biochem. 2015, 97, 165-174.

13. Yang, Z.; Yang, F.; Liu, J.L.; Wu, H.T.; Yang, H.; Shi, Y.; Liu, J.; Zhang, Y.F.; Luo, Y.R.; Chen, K.M. Heavy metal transporters: Functional mechanisms, regulation, and application in phytoremediation. Sci. Total Environ. 2021, 809, 151099. [CrossRef] [PubMed]

14. De Abreu-Neto, J.B.; Turchetto-Zolet, A.C.; de Oliveira, L.F.V.; Bodanese Zanettini, M.H.; Margis-Pinheiro, M. Heavy metalassociated isoprenylated plant protein (HIPP): Characterization of a family of proteins exclusive to plants. FEBS J. 2013, 280, 1604-1616. [CrossRef] [PubMed]

15. Tehseen, M.; Cairns, N.; Sherson, S.; Cobbett, C.S. Metallochaperone-like genes in Arabidopsis thaliana. Metallomics 2010, 2, 556-564. [CrossRef] [PubMed]

16. Khan, I.U.; Rono, J.K.; Zhang, B.Q.; Liu, X.S.; Wang, M.Q.; Wang, L.L.; Wu, X.C.; Chen, X.; Cao, H.W.; Yang, Z.M. Identification of novel rice (Oryza sativa) HPP and HIPP genes tolerant to heavy metal toxicity. Ecotoxicol. Environ. Saf. 2019, 175, 8-18. [CrossRef]

17. Zhang, X.; Feng, H.; Feng, C.; Xu, H.; Huang, X.; Wang, Q.; Duan, X.; Wang, X.; Wei, G.; Huang, L.; et al. Isolation and characterization of cDNA encoding a wheat heavy metal-associated isoprenylated protein involved in stress responses. Plant Biol. 2010, 17, 1176-1186. [CrossRef] [PubMed]

18. Khan, I.U.; Rono, J.K.; Liu, X.S.; Feng, S.J.; Li, H.; Chen, X.; Yang, Z.M. Functional characterization of a new metallochaperone for reducing cadmium concentration in rice crop. J. Clean. Prod. 2020, 272, 123152. [CrossRef]

19. Zhang, B.Q.; Liu, X.S.; Feng, S.J.; Zhao, Y.N.; Wang, L.L.; Rono, J.K.; Li, H.; Yang, Z.M. Developing a cadmium resistant rice genotype with OsHIPP29 locus for limiting cadmium accumulation in the paddy crop. Chemosphere 2020, 247, 125958. [CrossRef]

20. Lin, S.J.; Pufahl, R.A.; Dancis, A.; O'Halloran, T.V.; Culotta, V.C. A role for the Saccharomyces cerevisiae ATX1 gene in copper trafficking and iron transport. Int. J. Biol. Chem. 1997, 272,9215-9220. [CrossRef]

21. Robinson, N.J.; Winge, D.R. Copper metallochaperones. Annu. Rev. Biochem. 2010, 79, 537-562. [CrossRef]

22. Zhang, Y.; Chen, K.; Zhao, F.J.; Sun, C.; Jin, C.; Shi, Y.; Sun, Y.; Li, Y.; Yang, M.; Jing, X.; et al. OsATX1 interacts with heavy metal P1B-type ATPases and affects copper transport and distribution. Plant Physiol. 2018, 178, 329-344. [CrossRef] [PubMed]

23. Liu, X.S.; Feng, S.J.; Zhang, B.Q.; Wang, M.Q.; Cao, H.W.; Rono, J.K.; Chen, X.; Yang, Z.M. OsZIP1 functions as a metal efflux transporter limiting excess zinc, copper and cadmium accumulation in rice. BMC Plant Biol. 2019, 19, 283. [CrossRef] [PubMed]

24. Zhang, X.D.; Wang, Y.; Li, H.B.; Yang, Z.M. Isolation and identification of rapeseed (Brassica napus) cultivars for potential higher and lower Cd accumulation. J. Plant Nutr. Soil Sci. 2018, 181, 479-487. [CrossRef]

25. Feng, S.J.; Liu, X.S.; Ma, L.Y.; Khan, I.U.; Rono, J.K.; Yang, Z.M. Identification of epigenetic mechanisms in paddy crop associated with lowering environmentally related cadmium risks to food safety. Environ. Pollut. 2020, 256, 113464. [CrossRef] [PubMed]

26. Li, H.; Song, J.B.; Zhao, W.T.; Yang, Z.M. AtHO1 is involved in iron homeostasis in a NO-dependent manner. Plant Cell Physiol. 2013, 54, 1105-1117. [CrossRef] [PubMed]

27. Feng, S.J.; Liu, X.S.; Cao, H.W.; Yang, Z.M. Identification of a rice metallochaperone for cadmium tolerance by an epigenetic mechanism and potential use for clean up in wetland. Environ. Pollut. 2021, 288, 117837. [CrossRef] [PubMed]

28. Zhao, Y.N.; Wang, M.Q.; Li, C.; Cao, H.W.; Rono, J.K.; Yang, Z.M. The metallochaperone OsHIPP56 gene is required for cadmium detoxification in rice crops. Environ. Exp. Bot. 2022, 193, 104680. [CrossRef] 
29. Curie, C.; Cassin, G.; Couch, D.; Divol, F.; Higuchi, K.; Le Jean, M.; Misson, J.; Schikora, A.; Czernic, P.; Mari, S. Metal movement within the plant: Contribution of nicotianamine and yellow stripe 1-like transporters. Ann. Bot. 2009, 103, 1-11. [CrossRef] [PubMed]

30. Yadav, S.K. Heavy metals toxicity in plants: An overview on the role of glutathione and phytochelatins in heavy metal stress tolerance of plants. S. Afr. J. Bot. 2010, 76, 167-179. [CrossRef]

31. Clemens, S.; Deinlein, U.; Ahmadi, H.; Höreth, S.; Uraguchi, S. Nicotianamine is a major player in plant Zn homeostasis. Biometals 2013, 26, 623-632. [CrossRef] [PubMed]

32. Rono, J.K.; Wang, L.L.; Wu, X.C.; Cao, H.W.; Zhao, Y.N.; Khan, I.U.; Yang, Z.M. Identification of a new metallothionein-like gene OsMT1e for cadmium detoxification and potential phytoremediation. Chemosphere 2021, 265, 129136. [CrossRef] [PubMed]

33. Bocanski, J.; Sreckov, Z.; Nastasic, A. Genetic and phenotypic relationship between grain yield and components of grain yield of maize (Zea mays L.). Genetika 2009, 41, 145-154. [CrossRef]

34. Li, L.; Tong, H.; Xiao, Y.; Che, R.; Xu, F.; Hu, B.; Liang, C.; Chu, J.; Li, J.; Chu, C. Activation of Big Grain1 significantly improves grain size by regulating auxi transport in rice. Proc. Natl. Acad. Sci. USA 2015, 112, 11102-11107. [CrossRef] [PubMed]

35. Zhang, L.; Wang, R.; Xing, Y.; Xu, Y.; Xiong, D.; Wang, Y.; Yao, S. Sepqrable regulation of POW1 in grain size and leaf angle development in rice. Plant Biotech. J. 2021, 19, 2517-2531. [CrossRef]

36. Jiao, Y.; Wang, Y.; Xue, D.; Wang, J.; Yan, M.; Liu, G.; Dong, G.; Zeng, D.; Lu, Z.; Zhu, X.; et al. Regulation of OsSPL14 by OsmiR156 defines ideal plant architecture in rice. Nat. Genet. 2010, 42, 541-545. [CrossRef]

37. Mu, S.; Yamaji, N.; Sasaki, A.; Luo, L.; Du, B.; Che, J.; Shi, H.; Zhao, H.; Huang, S.; Deng, F.; et al. A transporter for delivering zinc to the developing tiller bud and panicle in rice. Plant J. 2020, 105, 786-799. [CrossRef]

38. Chen, G.; Xiong, S. OsHIPP24 is a copper metallochaperone which affects rice growth. J. Plant Biol. 2021, 64, 145-153. [CrossRef]

39. Swamy, B.P.M.; Rahman, M.A.; Inabangan-Asilo, M.A.; Amparado, A.; Manito, C.; Chadha-Mohanty, P.; Reinke, R.; Slamet-Loedin, I.H. Advances in breeding for high grain zinc in rice. Rice 2016, 9, 49. [CrossRef]

40. Yang, G.; Inoue, A.; Takasaki, H.; Kaku, H.; Akao, S.; Komatsu, S. A proteomic approach to analyze auxin- and zinc-responsive protein in rice. J. Proteome Res. 2005, 4, 456-463. [CrossRef]

41. Zhang, H.; Chen, T.; Wang, Z.; Yang, J.; Zhang, J. Involvement of cytokinins in the grain filling of rice under alternate wetting and drying irrigation. J. Exp. Bot. 2010, 61, 3719-3733. [CrossRef]

42. Gao, F.; Robe, K.; Gaymard, F.; Izquierdo, E.; Dubos, C. The transcriptional control of iron homeostasis in plants: A tale of bHLH transcription factors? Front. Plant Sci. 2019, 10, 6. [CrossRef] [PubMed]

43. Gao, S.; Xiao, Y.; Xu, F.; Gao, X.; Cao, S.; Zhang, F.; Wang, G.; Sanders, D.; Chu, C. Cytokinin-dependent regulatory module underlies the maintenance of zinc mutrition in rice. New Phytol. 2019, 224, 202-215. [CrossRef] [PubMed]

44. Wu, T.Y.; Gruissem, W.; Bhullar, N.K. Targeting intracellular transport combined with efficient uptake and storage significantly increases grain iron and zinc levels in rice. Plant Biotechnol. J. 2019, 17, 9-20. [CrossRef] [PubMed]

45. Lan, H.X.; Wang, Z.F.; Wang, Q.H.; Wang, M.M.; Bao, Y.M.; Huang, J.; Zhang, H.S. Characterization of a vacuolar zinc transporter OZT1 in rice (Oryza sativa L.). Mol. Biol. Rep. 2013, 40, 1201-1210. [CrossRef] [PubMed]

46. Menguer, P.K.; Farthing, E.; Peaston, K.A.; Ricachenevsky, F.K.; Fett, J.P.; Williams, L.E. Functional analysis of the rice vacuolar zinc transporter OsMTP1. J. Exp. Bot. 2013, 64, 2871-2883. [CrossRef] [PubMed]

47. Briat, J.F.; Duc, C.; Ravet, K.; Gaymard, F. Ferritins and iron storage in plants. Biochim. Biophys. Acta 2010, 1800, 806-814. [CrossRef]

48. Silveira, V.C.D.; Fadanelli, C.; Sperotto, R.A.; Stein, R.J.; Basso, L.A.; Santos, D.S.; Vaz Junior, I.D.S.; Dias, J.F.; Fett, J.P. Role of ferritin in the rice tolerance to iron overload. Sci. Agric. 2009, 66, 549-555. [CrossRef]

49. Li, L.; Ye, L.; Kong, Q.; Shou, H. A vacuolar membrane ferric-chelate reductase, OsFRO1, alleviates Fe toxicity in rice (Oryza sativa L.). Front. Plant Sci. 2019, 10, 700. [CrossRef] 